\title{
Interview
}

\section{Bryant and Sharer: seven challenges most likely to make-or-break leaders}

\section{Brian Leavy}

(C) Brian Leavy. Published by Emerald Publishing Limited. This article is published under the Creative Commons Attribution (CC BY 4.0) licence. Anyone may reproduce, distribute, translate and create derivative works of this article (for both commercial and non-commercial purposes), subject to full attribution to the original publication and authors. The full terms of this licence may be seen at http://creativecommons. org/licences/by/4.0/legalcode

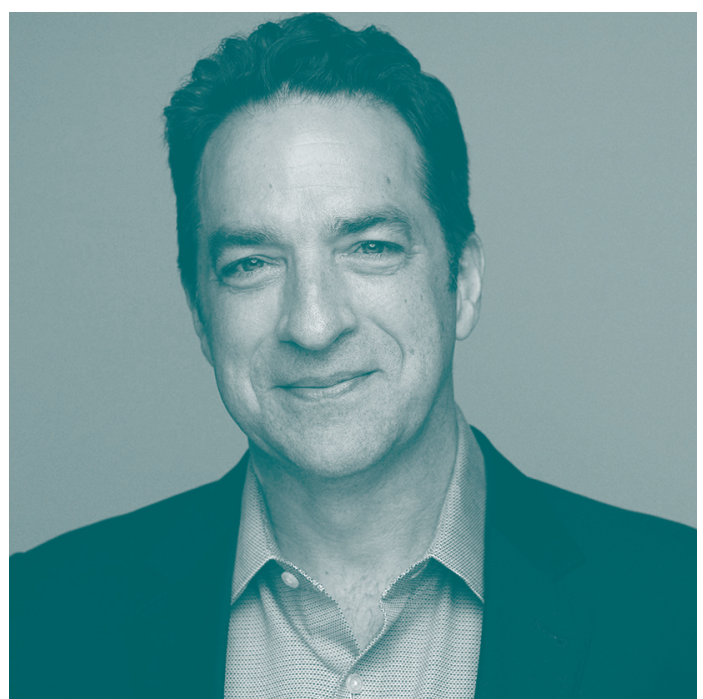

Adam Bryant

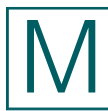

uch of the on-going outpouring of leadership literature tends to focus on the personal qualities and characteristics of the individual leader. Less studied are the dynamics of the relationship between the leader and the led, or the nature and content of the role itself and the key tasks associated with it. One exception is the recent book, Unleashed: The Unapologetic Leader's Guide to Empowering Everyone Around You, by France Frei and Anne Morriss, who offer insight into the dynamics of the relationship and the central role that building and losing trust can play in the ebb and flow of leadership effectiveness.[1]

Another notable new book with this perspective on leadership, The CEO Test: Mastering the Challenges that Make or Break All Leaders, by Adam Bryant and Kevin Sharer, examines the content of the role and the key challenges that tend to determine leadership success or failure.[2] Adam Bryant is managing director of Merryck \& Co., a leadership development and senior executive mentoring firm. He is also a former journalist for 30 years with the New York Times and author/creator of its successful "Corner Office" column. Kevin Sharer is the former CEO of Amgen, the world-leading biotech company, and he has also taught strategy and management at Harvard Business School for seven years. The CEO Test draws on the combined insights from Bryant's 600+ executive interviews and Sharer's extensive leadership experiences.

Strategy \& Leadership's interviewer is contributing editor Brian Leavy, Emeritus Professor of Strategy at Dublin City University Business School (brian.leavy@dcu.ie).

Strategy \& Leadership: Given the extensive literature on leadership, where did you see the need and opportunity to offer something different in your new book and how and where do you see it adding most value?

Adam Bryant and Kevin Sharer: For all that's been written about leadership, we believe that the challenges of leadership remain enormously difficult and elusive for people at every level and across all types of organizations from businesses to non-profits to the public sector. So we are asking and answering foundational questions such as, "What are the challenges that make or break all leaders?" and "What is the playbook for how to lead others effectively?" Many 
discussions about leadership tend to be about life in general, such as the importance of trust and authenticity. We focus specifically on leading others - illuminating seven of the most common make-or-break challenges, and then showing how to navigate them effectively.

While the challenges we focus on are brought into their sharpest relief in the breadth and complexity of the CEO job, if leaders at all levels can learn how to recognize and navigate them, then they are more likely to succeed in their current and future roles.

\section{Effective leadership - six defining "must do" challenges}

$S \& L$ : You identify six major "must do" challenges and one major "must be" challenge facing CEOs. They also offer lessons for leaders at every level.

The first "must do" challenge: Can leaders develop a simple plan for their strategy that will get everyone moving in the same direction? And you see the key leadership skill as the ability "to simplify complexity." Why is this so challenging?

Bryant and Sharer: When you ask some people about their strategy, they may go to a very high altitude, sharing generalities about what the company does. At the other extreme, executives can get very granular, saying that their strategy is the ten priorities they are working on just for the next quarter. What is often missing is a middle layer that answers the simple questions of where are we going and how are we going to get there? The most effective model for setting strategy we've encountered comes from Dinesh Paliwal, the former CEO of Harman International. $\mathrm{He}$ advocates a one-page exercise that has an overarching goal of what the company wants to achieve over a certain period, which might be shorter for start-ups and longer for bigger and more established companies; the three or four levers that a company has to pull to achieve the goal; the challenges that have to be overcome; and a scoreboard for measuring progress and success.

Simplifying complexity is an important and rare skill of leadership. It's the leader's job to capture the essence of what matters and then be able to boil down the strategy to just a handful of memorable ideas so that everyone understands, remembers and knows how to contribute to its success. At Disney, for example, CEO Bob Iger said that the company would focus on embracing technology in all its forms, developing great content and global expansion, and these have been the guiding principles of Disney's growth under his leadership.

S\&L: How can leaders best develop and hone this skill in practice and what are some of the main pitfalls to be avoided?

Bryant and Sharer: It takes discipline to constantly push yourself to sharpen your strategy and your message. If you have a list of ten points, can you cut them to five, and then three? Can you create a simpler framework where some of the ideas "nest" inside others? Leaders also need to guard against a phenomenon that we call "expert-itis." They can be too close to their subject, and so what seems obvious and clear to them isn't obvious to others. To close that gap, leaders, once they have developed a simple strategy, can take it to their teams and use them as a focus group. Is this clear to you? Do you see how it will help us win as an organization? Do you understand how your role helps drive this overall strategy?

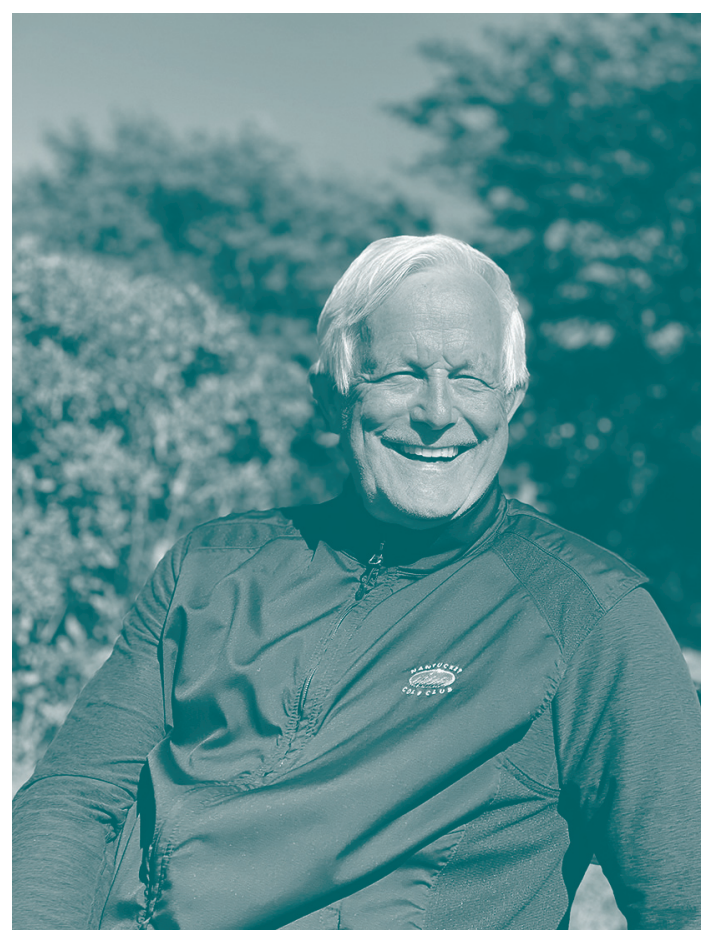

Kevin Sharer 
S\&L: A closely related "must do" challenge for leaders is "making the culture real and matter." Why is this so important and what makes it so difficult?

Bryant and Sharer: Culture, like strategy, can mean different things to different people. Yet, it can be an enormous point of leverage for companies. Done right, culture will interact with something within employees' sense of themselves, ideally in ways that are aligned with the strategy and help make it more engaging for them. Work then becomes more of their identity - what they stand for, the contributions they want to make, what they aspire to be. Leaders who get culture right will have everyone pulling in the same direction, and they are able to focus more on the work itself rather than navigating all the internal politics and games that are endemic to unhealthy cultures.

S\&L: Given that the whole notion of corporate culture "can be messy and maddening" for many leaders, what guiding principles can you offer to help them meet this test in practice?

Bryant and Sharer: While there is no right culture or definitive blueprint, the cornerstone of a strong cultural foundation is having a clear set of values. These values, and the specific behaviors they are meant to promote, carry particular weight in the life of an organization because they help address the simple, but often challenging question: How are we going to work together? For the values to really matter the leadership team needs to clearly own and embody them, talk about them at all-hands meetings and tell stories of how people have brought them to life. Quarterly and annual awards are also effective for reinforcing their importance.

The values have to be woven into the fabric of the organization's everyday life, including the hiring and on-boarding process, and employees need to be reminded of them at all the key touchpoints of working at the company. Persistent failure to embrace and support them should be seen as grounds for sanction or dismissal.

$S \& L$ : The third major challenge is, can leaders build a "true" team? What are the key issues to be addressed in building a true team and how will you know when you've succeeded?

Bryant and Sharer: Teams are the key to driving the strategy, but nobody should expect that assembling a group of high-achieving executives and calling them a team will make them act like a team. Getting them to work effectively with their peers, even when they may be competing for resources, requires intentional effort from the person leading the team. We believe there are four key questions that every leader must answer for a team to be effective:

- What is the purpose of the team (what are the big strategic lifts that will need our combined force and what will success look like to us)?

- Who should be on the team?

- How will the team work together?

- What is the leader's role on the team?

\section{"We focus specifically on leading others - illuminating} seven of the most common make-or-break challenges, and then showing how to navigate them effectively." 


\section{"It's the leader's job to capture the essence of what matters and then be able to boil down the strategy to just a handful of memorable ideas so that everyone understands, remembers and knows how to contribute to its success."}

While building, managing, and developing a team can seem like a full-time job on its own, the investment in time will pay dividends if leaders focus on addressing these foundational questions to ensure that the team is operating at its highest possible level.

The most common pitfalls that leaders run into include:

- Not setting clear enough ground-rules for debate and disagreement to ensure that people feel safe when speaking up.

- Not establishing clear agendas for meetings.

- Not ensuring everyone is heard.

- Not putting enough effort into coaching individual team members to help them grow and become more effective.

$S \& L$ : In today's highly dynamic and complex environment the question of whether you can lead ongoing transformation is the fourth leadership test. What should be the most important elements in any leader's transformation playbook and what are the most consequential missteps leaders tend to make in this important area?

Bryant and Sharer: The biggest misstep in transformation efforts is a top-down approach, with the CEO announcing "here is my plan" and then expecting everyone to fall in line to execute the idea. It rarely works, in part because the status quo is such a powerful force. People will resist change, because change means uncertainty. The key steps of building a successful transformation effort start with creating a compelling narrative to show that change is both necessary and desirable, because it will lead to a better place. The next step is to clearly articulate what is not going to change, particularly mission or purpose, so that employees are more open to new approaches. Then leaders at all levels of the organization need to be engaged to help contribute to the specific strategies for change - and ensure that all ideas get an appropriate airing, rather than being shut down by people who are acting out of self-interest to protect their turf. Then communicate relentlessly, particularly about small wins, to create a sense of momentum.

$S \& L$ : Can you "really listen" is the fifth leadership test. Listening "is an essential skill for leaders to counteract the many powerful forces that conspire to trap them in dangerous bubbles." How can leaders improve their listening skills?

Bryant and Sharer: Even though CEOs have access to more lines of communication in their organizations than anyone else, the quality of the information they get is often filtered and suspect. Leaders become trapped in a bubble, and so they have to make an extra effort to know what's really happening in their organizations. And very often, leaders themselves contribute to this problem by sending clear, even if unintended, signals that they don't want to hear bad news or dissenting opinions.

To break through the bubble, leaders have to learn that listening is a multidimensional practice that requires commitment and constant attention, and the aim is to get a true sense of the nature of their organization and its dynamics, and what it feels like to their people at all levels. One step is to ensure all employees 
have a direct line of communication to the CEO - through email and through regular surveys of employees. Many CEOs we've interviewed hold regular meetings with employees from all levels of the company to draw them out with questions such as, "What should I know that I don't know?" Part of the solution is to set a tone that bad news is not going to be punished. One CEO, for example, tells his team that if they have bad news, they should text him right away. If it's good news, they should wait to tell him in person.

S\&L: The sixth test is, can leaders handle a crisis? The current Covid19 pandemic is a reminder that the likelihood of crisis, whether external or internal, is the ominous scenario haunting leadership today. What are the main elements in your recommended playbook for handling an external shock like the pandemic?

Bryant and Sharer: The first is to see a crisis like the pandemic as an opportunity, not just a challenge, and to capitalize on the sense of urgency. In fact, many of the core business skills that companies typically struggle with - prioritization, speed of decision making, and innovation - often become much easier in a crisis. As a result, issues that previously seemed impossible to tackle, like remote working, are suddenly on the table. It's an opportunity to reimagine the company and ask foundational questions such as, "If we were building the company today from scratch, what would we do differently? And once we get beyond this crisis, where do we want to be a year from now, three years from now, and what resources would be required to get there?"

Also, leaders in a crisis need to be more visible than usual because they need to set the tone through their words, deeds and body language. Navigating a crisis like the pandemic requires using very different leadership muscles at different moments. For example, there are times that require leaders to be compassionate about the strain that people are under, and other moments when they must require the team to step up and deliver their best, with a clear sense of accountability.

$S \& L$ : What are the biggest mistakes that leaders tend to make when the crisis is internal, and what advice do you have to help navigate an internal crisis successfully?

Bryant and Sharer: While the playbook for leading through a crisis is not particularly complex, putting it into practice when you are in the middle of an internal crisis can be much harder. The most common problem initially is denial and the biggest mistake that leaders tend to make is saying things to try to downplay the crisis that go beyond what they really know and may later come to regret. Even one well-meaning but untrue statement at the outset of a crisis can squander the most precious resource you have your credibility - which is almost impossible to get back. So leaders need to follow a straightforward playbook of projecting calm, getting all the facts about the extent of the problem, acting quickly and transparently to communicate to key stakeholders and signal a determination to get to the cause and ensure that the internal lapses that led to it don't happen again.

"Done right, culture will interact with something within employees' sense of themselves, ideally in ways that are aligned with the strategy and help make it more engaging for them." 


\section{"The key steps of building a successful transformation effort start with creating a compelling narrative to show that change is both necessary and desirable, because it will lead to a better place."}

Who a leader must be - the seventh defining challenge

S\&L: Your seventh and final test shifts the focus onto who leaders "must be" to be successful. What's your advice to leaders to help them achieve an effective level of selfawareness and comfort with who they are in the face of the role's inevitable pressures?

Bryant and Sharer: Leadership is hard, and our overarching framework to mastering the inner game of leadership is to embrace it as a series of paradoxes. Understanding leadership as a series of contradictions is the first step to making sense of all the whiplashinducing advice you will be offered in this field. For example, when taking on a new leadership role, many argue that you should make quick decisions to show urgency and impact. Others counsel patience, in order to listen and really understand the root issues. When they are faced with the ever-shifting variables of leadership, people understandably latch on to one approach, telling themselves that they have developed their own leadership style, and that others need to accommodate it. Insecure in the shades of grey and contradictions of leadership, they become terrible managers because they get frustrated that the world is not bending to their will. When people ask themselves whether they should act one way or another in a particular situation, the answer is often both, depending on the circumstances.

By framing such challenges as paradoxes, leaders will have a useful framework for making sense of the minute-to-minute tests and can flex one way or another depending on the needs of the moment. The most common paradoxes we see are that leaders need to be both confident and humble; urgent and patient; compassionate and demanding; optimistic and realistic. Learning to find their own balance point will tend to come with experience, but only if leaders are already aware that this is what they should be searching for in their ongoing development.

S\&L: Finally, perhaps the most personal paradox is this: "the best leaders are selfless" yet "if you aspire to be that selfless leader then you must learn to take care of yourself first." What principal guidelines do you offer to help leaders with this challenge?

Bryant and Sharer: Top leadership jobs are endurance tests. Not only do they require tremendous stamina, but they also require a thick skin to handle the relentless criticism and second-guessing. It is easy for leaders to feel as if they are losing control of their lives to the job, because there is always more to do, and there are always crises, both small and large. To remain effective in their jobs and not be overwhelmed, leaders have to take care of themselves first so that they can help others. That includes getting enough exercise and rest, of course, but it also requires setting a few achievable goals and delegating as much as possible to the team.

\section{Notes}

1. Frei, F. and Morriss, A. (2020). Unleashed: The Unapologetic Leader's Guide Empowering Everyone Around You, Boston: Harvard Business Review Press.

2. Bryant, A. and Sharer, K. (2021). The CEO Test: Master the Challenges That Make or Break All Leaders, Boston: Harvard Business Review Press. 


\section{The seven CEO tests}

1. Can you develop a simple plan for your strategy?

- Simplifying complexity is a leader's superpower

2. Can you make the culture real - and matter?

- It's about walking the talk

3. Can you build teams that are true teams?

- They are the key to driving strategy

4. Can you lead transformation?

- The status quo is extremely powerful, and the enemy of change

5. Can you really listen?

- Danger signals can be faint, and bad news travels slowly

6. Can you handle a crisis?

- Avoid the predictable mistakes that trip up so many leaders

7. Can you master the inner game of leadership?

- The conflicting demands and challenges must be managed

\section{Corresponding author}

Brian Leavy can be contacted at: brian.leavy@dcu.ie

For instructions on how to order reprints of this article, please visit our website: www.emeraldgrouppublishing.com/licensing/reprints.htm

Or contact us for further details: permissions@emeraldinsight.com 